\title{
Relations among personal initiative and the development of reading strategy knowledge and reading comprehension
}

\author{
Greta J. Warner, Doris Fay, \& Nadine Spörer
}

University of Potsdam, Germany

Article received 28 September / revised 21 December / accepted 27 December / available online 28 February

\begin{abstract}
Reading comprehension is a self-regulated activity that depends on the proactive effort of the reader. Therefore, the authors studied the effects of personal initiative (PI) on the development of reading comprehension, mediated by reading strategy knowledge. Structural equation modelling was applied to a longitudinal study with two data waves separated by two years. At Time 1 , the participants $(N=1,102)$ were either in third or fourth grade. At Time 2, third graders had moved to grade five, and fourth graders had moved to grade six $(N=1,009)$. At both grade levels, PI explained unique variance in reading strategy knowledge and reading comprehension at Time 2. Moreover, from fourth to sixth grade the effect of PI on reading comprehension was mediated by reading strategy knowledge. No mediation was observed from third to fifth grade. These findings emphasize the relevance of PI in the development of reading strategy knowledge and reading comprehension. They further reveal that the hypothesized mediation process does not unfold until sixth grade.
\end{abstract}

Keywords: personal initiative; self-regulation; reading comprehension; strategy knowledge; proactivity 


\section{Introduction}

Reading comprehension is understood as a multifaceted and constructive process in which basic information processes and higher cognitive skills must be coordinated and self-regulated (e.g., Cain, Oakhill, \& Bryant, 2004). Readers must identify word meanings, actively construct text meanings, and embed text information into previous knowledge (Kintsch, 1998). The orchestration of these micro- and macroprocesses requires that students have a clear goal in mind, plan ahead, and stay persistent when comprehension is challenged (e.g., Duke \& Pearson, 2002). Therefore, they need to be highly proactive, take responsibility, and demonstrate a good deal of personal initiative (e.g., Dermitzaki, Andreou, \& Paraskeva, 2008).

Personal initiative (PI) defines the behavioural tendency to show self-starting, proactive, and persistent behaviour (see Frese \& Fay, 2001; Wollny, Fay, \& Urbach, 2016). In present theories of selfregulated learning this proactive behaviour is understood as an essential antecedent of successful learning processes (e.g., Zimmerman, 2002). Thus, it seems likely that PI has an impact on students' academic performance (Wollny et al., 2016). Yet, research in this area is only just beginning to develop and until now, no study has focused on the impact of PI on one of the most important academic abilities and predictors of future academic performance, i.e., reading comprehension.

To date, most empirical studies have focused on the relevance of basic cognitive self-regulatory skills in the development of reading comprehension. For example, there is substantial evidence that executive functions predict reading comprehension in the long-term (e.g., Birgisdóttir, Gestsdóttir, \& Thorsdóttir, 2015). These and similar self-regulatory skills are relevant because they reflect a child's ability to respond to classroom requirements (e.g., follow instructions; McClelland \& Cameron, 2011). In addition to these elementary self-regulatory abilities, we propose that PI adds to the literature by capturing the self-starting, proactive, and persistent nature of reading comprehension as emphasized by both researchers and educators (e.g., Horner \& Shwery, 2002; Pressley \& Afflerbach, 1995). PI should, for example, demonstrate a particularly high relation to active reading behaviours, like goal-setting and active problem-solving (e.g., Pressley \& Afflerbach, 1995).

However, there seems to be a lack of research about how these proactive behaviours impact the early development of reading comprehension during later school years at elementary school. As of third or fourth grade, students start switching from rather basic word reading to a more global text understanding (e.g., Duke \& Carlisle, 2011). Their ability to reflect about their thinking starts developing (i.e., metacognition). This builds the foundation for strategy use, planning, and problem-solving behaviours as involved in PI (e.g., Janke \& Hasselhorn, 2008; Schneider, 2010). Thus, both reading comprehension and PI likely show a rapid development during that time making it a critical timeframe for studying their relations. The first aim of this study is therefore to explore whether PI represents a predictor of reading comprehension from third to fifth and fourth to sixth grade.

In addition, research so far has paid little attention to the mediational mechanisms that explain a positive relation between domain-unspecific self-regulatory constructs and a specific academic ability, such as reading comprehension (e.g., Best, Miller, \& Jones, 2009). Yet, it is emphasized that general selfregulatory tendencies do not directly, but rather indirectly affect academic performance via more specific learning-oriented actions (e.g., Boekaerts, 1999; Borkowski, Chan, \& Muthukrishna, 2000). Therefore, it is necessary to develop a better understanding of how more general and domain-specific self-regulatory processes interact to influence academic performance. In this study, we assume the effects of PI on reading comprehension to be mediated by self-regulatory skills gained during the reading process. Within this context, adequate reading strategy knowledge constitutes one crucial self-regulatory skill, which has consistently demonstrated positive associations with reading comprehension (van Kraayenoord, 2010). Hence, a second aim of this study is to investigate a mediational process in which PI affects reading comprehension via the development of reading strategy knowledge. 
Demonstrating such a mediational process and thereby a positive impact of PI on reading comprehension would have important theoretical and educational implications. First, it would emphasize the relevance of proactivity in the development of reading comprehension. Second, it would offer new insights into the relations between domain-unspecific self-regulatory tendencies and reading-specific selfregulatory actions. And third, it would suggest new directions in educational practices and encourage more opportunities of autonomy, choice, and control for students.

\subsection{Personal initiative and reading comprehension}

Initially developed within the work context (Frese \& Fay, 2001; Frese, Fay, Hilburger, Leng, \& Tag, 1997), the construct of PI represents the behavioural tendency to display self-starting, proactive, and persistent change-oriented behaviour (Frese \& Fay, 2001). Self-starting means setting goals that are not explicitly given and go beyond what is expected. Proactive means anticipating and acting towards future problems instead of waiting until problems arise. And, persistent means pursuing goals despite potential setbacks or other barriers. In other words, PI represents the opposite of "doing what one is told to do, giving up in the face of difficulties, and reacting to environmental demands" (Fay \& Frese, 2001, p. 97). Thus, PI describes behavioural components that have been put forward as core qualities of successful learners, such as the guidance by personal goals, systematic planning, and high perseverance (Zimmerman, 2002).

With this definition, PI is distinct from the concept of engagement because engagement includes adaptive behaviours that are not proactive in nature (e.g., doing homework, attending school; Jimerson, Campos, \& Greif, 2003). Likewise, PI is distinct from motivational variables (e.g., self-efficacy, goal orientation), which relate to a broad range of learning behaviours that are not necessarily proactive (e.g., engagement; Caraway, Tucker, Reinke, \& Hall, 2003). Finally, PI is distinct from self-regulated learning because it defines a general tendency rather than a process of learning-related activities (Wollny et al., 2016; Zimmerman, 2002).

Based on previous studies, we assume that successful reading comprehension requires all facets of PI. Pressley and Afflerbach (1995) studied think-aloud protocols of reading and found that good comprehenders were self-starting because they approached texts with a specific purpose in mind, set goals before and during reading, and constantly compared them with their reading progress. Good comprehenders were also proactive because they scanned the text, generated hypotheses, anticipated potential problems, and planned how to read the text. Finally, they were also persistent, tried new reading strategies, flexibly applied strategies, and discarded inefficient ones.

Quantitative studies underpin these results by showing that reading comprehension is selfdirected and self-reliant: Skilled reading comprehenders display more deliberate reading strategies and rely less on the support of other people than weak comprehenders (e.g., Botsas \& Padeliadu, 2003; Denton et al., 2015). Moreover, skilled comprehenders help themselves more actively: They use more problem-solving strategies and a larger variety of reading strategies when texts become difficult (Cantrell \& Carter, 2009; Kletzien, 1991). And, interventions that seek to enable students to become self-regulated and proactive were found to be more effective in promoting reading comprehension than teaching cognitive reading strategies alone (e.g., Dignath, Buettner, \& Langfeldt, 2008; Schünemann, Spörer, \& Brunstein, 2013). Taken together, these results suggest that the level of reading achievement depends on how actively, self-reliant, and persistently students regulate their own reading process. Accordingly, PI was found to predict active reading behaviour and individual word reading trajectories at elementary school beyond the effects of intrinsic motivation (Warner, Fay, Schiefele, Stutz, \& Wollny, 2016; Wollny, 2015). Moreover, reading achievement has been found to be affected by students' task-focused and engaged behaviour (e.g., DiPerna, Volpe, \& Elliott, 2005; Hirvonen, Georgiou, Lerkkanen, Aunola, $\&$ Nurmi, 2010). Yet, direct evidence pertaining to a positive relation between PI and children's reading comprehension development is missing so far. 


\subsection{The mediating role of reading strategy knowledge}

Reading strategy knowledge refers to the knowledge about what reading strategies can be applied, how strategies can be used, and under which conditions they should be used (Paris, Lipson, \& Wixson, 1983). With this, reading strategy knowledge represents a specific type of metacognitive knowledge (the knowledge about one's own and others' thought processes; Pintrich, 2002). According to Boekaert's theory of self-regulated learning (1999), the development of metacognitive knowledge represents an intermediate process between more general self-regulatory tendencies and the actual use of cognitive strategies. Thus, the development of reading strategy knowledge should be affected by a child's general tendency to display PI. Moreover, reading strategy knowledge should represent a prerequisite for the efficient use of reading strategies and thereby also for successful reading comprehension.

Reading strategy knowledge develops when students practice reading strategies on their own, take an active approach in their learning process, and choose moderately difficult texts (Borkowski et al., 2000; Gourgey, 1998; McKeachie, 1987). PI should provide an advantage within this process. Because children who score higher on PI are self-starting, we propose that they show spontaneous use of reading strategies even when not instructed to do so. Because they are proactive, we suggest that they realize the long-term benefits of reading strategies and thus are more motivated in acquiring new strategies. Moreover, when faced with reading failure, they likely stay persistent and apply a range of problemsolving strategies. And finally, because they are learning-oriented (Wollny et al., 2016), we assume that they choose challenging texts that require the use of reading strategies.

The development of higher strategy knowledge in turn is thought to promote the development of reading comprehension (Borkowski et al., 2000). This assumption rests upon the theoretical considerations and empirical findings that strategy knowledge results in higher frequency and efficiency of strategy usage, which, finally, results in higher reading comprehension (Borkowski et al., 2000; KolićVehovec, Zubković, \& Pahljina-Reinić, 2014). For example, van Kraayenoord and Schneider (1999) found that reading strategy knowledge predicted reading comprehension in third and fourth grade students. Thus, we assume that PI is a critical factor contributing to the independent use of strategies and thereby also to the acquisition of more reading strategy knowledge. Reading strategy knowledge in turn defines a relevant predictor of reading comprehension. These theoretical suggestions and empirical findings imply that reading strategy knowledge should act as a mediator between PI and the development of reading comprehension.

\subsection{The present study}

Reading comprehension is commonly described as the result of a highly active process which is self-starting, proactive, and persistent in nature (e.g., Pressley \& Afflerbach, 1995). However, when reviewing the literature two shortcomings become apparent. First, many studies addressed the role of rather basic self-regulatory skills, whereas constructs with an explicit focus on the proactive aspects of self-regulation have received less attention. And second, although a growing body of research has demonstrated positive relations between reading comprehension and domain-unspecific self-regulatory measures, little research exists on the mediating processes of these relations.

The present study therefore investigated the following research questions: 1) Does PI positively predict the development in reading comprehension? 2) Does PI contribute to reading comprehension through the development of reading strategy knowledge? Based on the literature reviewed, we hypothesized that PI contributes to students' development in reading comprehension over time (Hypothesis 1). As a mediating process we expected positive indirect contributions of PI to reading comprehension that are mediated by reading strategy knowledge (Hypothesis 2). We used a large-scale longitudinal study with two data collection points to examine these proposed associations. The hypothesized model is displayed in Figure 1. 
The model included measures of PI and reading comprehension at Time 1 and Time 2. We assessed PI also at a second time point because this controls for spurious relations and leads to more accurate estimates of the direct and indirect effects (e.g., Kenny, 1975; Little, Preacher, Selig, \& Card, 2007). We examined reading strategy knowledge only at Time 2 because previous evidence indicates that children's reading strategy use is underdeveloped at early grade levels (e.g., Kolić-Vehovec \& Bajsanski, 2001; Myers \& Paris, 1978) and therefore their self-reported strategic behaviour demonstrates low or none relations with reading performance (e.g., Wernke, 2012). Because reading comprehension is thought to affect the development of reading strategy knowledge (e.g., Borkowski et al., 2000), we also assumed an effect from Time 1 reading comprehension to Time 2 reading strategy knowledge.

We took effects of grade level into account and examined the proposed mediational process in two groups of elementary students. Students of Group 1 attended the third grade at Time 1 and the fifth grade at Time 2. Students of Group 2 attended the fourth grade at Time 1 and the sixth grade at Time 2 . Comparing these two groups provides useful information for future interventions in revealing whether the proposed developmental mechanisms can be generalized across grades or whether they differ by grade level because of developmental dynamics and progress in classroom instruction.

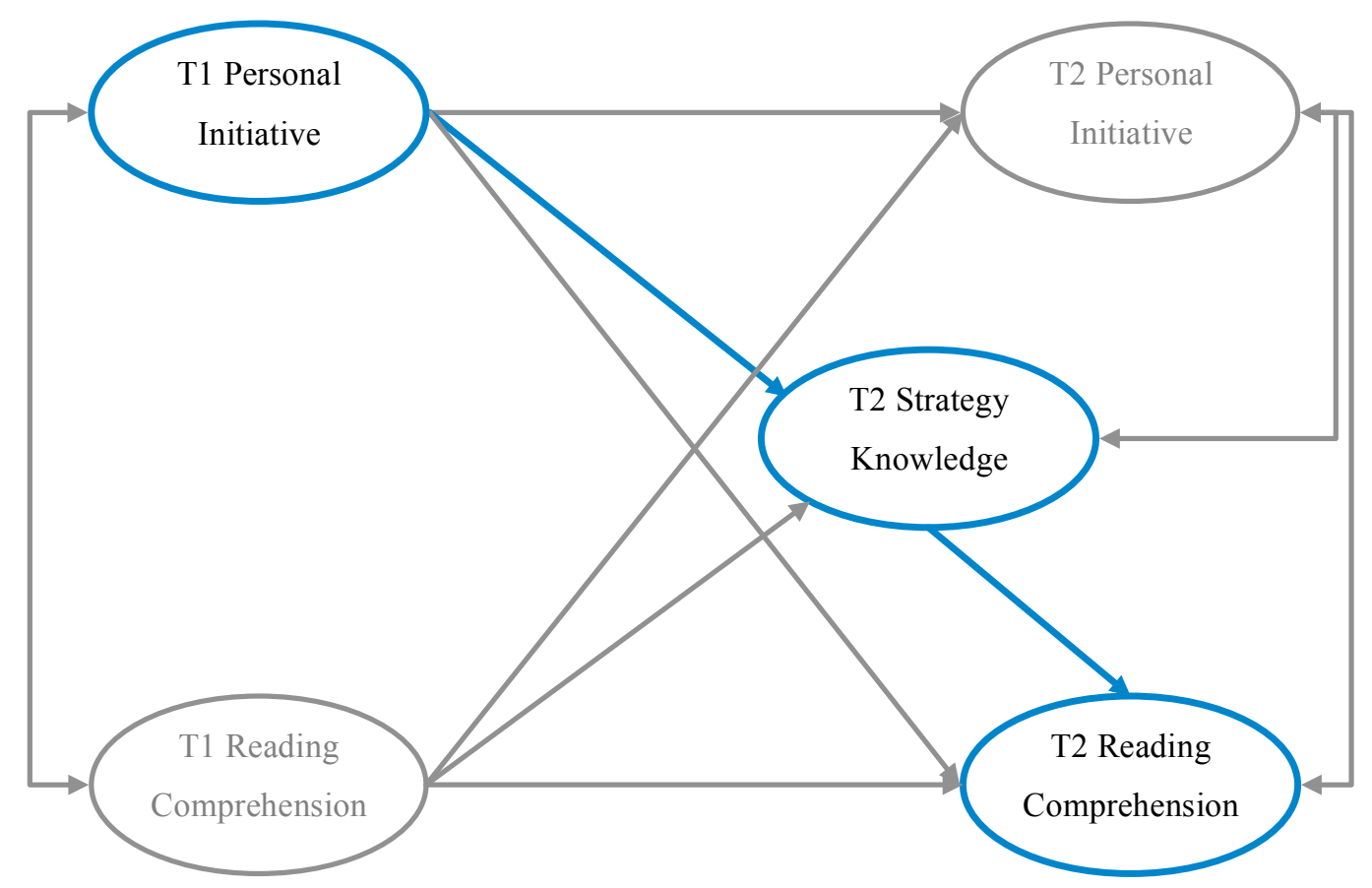

Figure 1. Hypothesized structural equation model.

\section{Method}

\subsection{Sample and procedure}

The present research is part of a larger project on intrapersonal risk and protective factors in the development of children and adolescents (PIER study). Because children were studied on a range of protective and risk factors, only limited time was available for each measure. A school-based sampling 
method was used to recruit children and their parents. First, 110 schools from different socioeconomic backgrounds were asked to take part in the study. After schools agreed to participate, parents of first-, second-, and third-grade students were informed about the aims of the study and were asked to participate. This resulted in 1657 children who took part at the first measurement wave (Time 0 ) of the project (580 families refused). The present study focused on the second (Time 1) and third measurement wave (Time 2) and examined two groups of elementary students and their parents or legal guardians.

Group 1 consisted of students who attended third grade at Time 1 and fifth grade at Time 2. This group included 546 students from 66 classes at Time $1\left(M_{\text {Age }}=9.09, S D=0.49 ; 52 \%\right.$ girls $)$. Group 2 consisted of students who attended fourth grade at Time 1 and sixth grade at Time 2. This group comprised 556 students from 56 classes at Time $1\left(M_{\text {Age }}=10.05, S D=0.45 ; 51 \%\right.$ girls $)$. At the first wave (Time 0 ), we did not use any measures of reading comprehension because students had not yet achieved this skill level. However, we obtained one of the control measures at this point in time (see below). The time interval between Time 0 and Time 1 was approximately nine months $\left(M_{\mathrm{t} 1-t 0}=8.9\right.$ months, $S D=1.7$ months) and between Time 1 and 2 approximately two years $\left(M_{\mathrm{t} 2-\mathrm{t} 1}=23.5\right.$ months, $S D=1.6$ months). Students came from 36 different schools in the federal state of Brandenburg (Germany). At each wave, trained university students tested the school students individually in two separate one-hour sessions. At about the same time, parents were requested to fill in a questionnaire that included measures capturing their child's behaviour and personality.

\subsection{Measures}

\subsubsection{Personal initiative at Time 1 and 2}

PI was assessed by means of an 8-item parent questionnaire (Wollny et al., 2016). The questionnaire includes four subscales, each measuring one aspect of PI: self-starting $\left(\alpha_{t 1}=.57, \alpha_{t 2}=.67\right.$; e.g., "My child independently searches for new tasks."), proactive $\left(\alpha_{t 1}=.82, \alpha_{t 2}=.81\right.$; e.g., "My child actively approaches problems."), persistent $\left(\alpha_{\mathrm{t} 1}=.72, \alpha_{\mathrm{t} 2}=.74\right.$; e.g., "If my child has independently set itself a learning goal, then it persistently pursues it."), and extra-role behaviour $\left(\alpha_{t 1}=.86, \alpha_{t 2}=.88\right.$; e.g., "My child takes initiative, even if others do not."). Answers were given by the mother or father of the child on a five-point scale ranging from 1 (does not apply at all) to 5 (fully applies). The internal consistency was high $\left(\alpha_{\mathrm{t} 1}=.88 ; \alpha_{\mathrm{t} 2}=.90\right)$. The questionnaire was identical to that constructed by Wollny et al. (2016).

\subsubsection{Reading comprehension at Time 1}

As an indicator for previous reading comprehension, we used the reading comprehension section from the ELFE test (Lenhard \& Schneider, 2006). Due to time constraints and concerns about training effects, we split the original test into two halves and applied only one of these halves at Time 1 (see Stutz, Schaffner, \& Schiefele, 2016). Students had three and a half minutes to read six short narrative text passages followed by one or two multiple-choice questions. To correctly choose the right answer, students had to find isolated information from the text, make interferences, and build anaphoric relations. At any time, the text passages were available to students. The internal consistency was adequate $(\alpha=.79)$.

\subsubsection{Reading comprehension at Time 2}

To measure reading comprehension at Time 2, students read an expository text "Die Tiefsee" (the deep sea) from the German reading test LESEN 6-7 (Bäuerlein, Lenhard, \& Schneider, 2012). Due to time constraints, we shortened the original text by $42 \%$ of its length (from 550 to 320 words) and reduced the original 17 multiple-choice items to 10 items. We primarily excluded items on word-, sentence-, and text knowledge in favour of retaining items that required the building of anaphoric inferences and a 


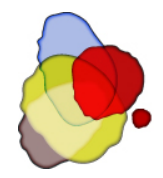

mental model of the text (e.g., "What title would match this text?"). At any time, students were allowed to look back into the text. The internal consistency of the shortened version was acceptable $(\alpha=.70)$.

\subsubsection{Reading strategy knowledge at Time 2}

To measure reading strategy knowledge, we developed a self-report questionnaire based on selected strategy questionnaires by Wernke, Wagener, Anschuetz, and Moschner (2011), Wild and Schiefele (1994), Pintrich (1991), and Lompscher (1995). Items of these questionnaires were rephrased in the way that they measure strategy knowledge and not the actual use of strategies. Moreover, we took care only to select items which we judged to be helpful for the reading comprehension test at Time 2 . The resulting nine items assessed knowledge about elaboration strategies (4 items, e.g., "Are you familiar with trying to visualize objects, situations, or characters that occur in the text?"), combined organization/elaboration strategies (4 items, e.g., "Are you familiar with trying to identify the most relevant information of a text section?"), and control strategies (1 item, e.g., "Are you familiar with going back in the text and looking at and reading again some text passages and sections?"). Elaboration strategies help to embed new information into prior knowledge, organization strategies facilitate the structuring of new information, and control strategies support the monitoring of comprehension (Weinstein \& Mayer, 1986).

Answers were given on a three-point scale ranging from no, I've never heard before, to yes, I've heard before, and yes, I know how to do it. To prevent priming effects, reading comprehension was measured at Session 1, whereas strategy knowledge was assessed at Session 2 (approximately five days later). We applied exploratory factor analysis with oblique rotation (Geomin) in Mplus to explore the factor structure of the questionnaire. As extraction method we used the model fit and the theoretical plausibility of factor solutions. The questionnaire demonstrated a unidimensional structure, which was supported by confirmatory factor analysis, $\chi^{2}(27)=123.01, p<.001$, CFI $=.966$, RMSEA $=.059$. Ordinal alpha was also adequate $(\alpha=.86$; Gadermann, Guhn, $\&$ Zumbo, 2012). To test the validity of the measure, we included one item that presented a non-existing reading strategy, i.e., the "green-paper strategy" ("Are you familiar with working on a text by using the green-paper strategy?"). While some students reported to have heard of this strategy $(n=110)$, only $2.7 \%(n=30)$ of the total sample reported to know how to apply this strategy. We see this as some indication of a valid assessment of strategy knowledge. Finally, compared to sixth grade students $(n=60)$ a higher proportion of fifth grade students $(n=80)$ reported to have heard from or to know this strategy, $\chi^{2}(2)=7.80, p=.020$.

\subsubsection{Control variables}

Reading performance and strategic skills draw to some extent on an individual's basic cognitive skills, gender, and socioeconomic status (e.g., Artelt, Naumann, \& Schneider, 2010; Bowey, 2005; Chiu $\&$ McBride-Chang, 2006). Thus, to ensure that effects of PI were robust against the influence of these variables, we controlled for gender, the number of books at home (as a measure of socioeconomic status), and a measure of cognitive ability assessing different aspects of nonverbal intelligence (Digital Symbol Substitution test; Petermann \& Petermann, 2008). Parents rated the number of books at home at Time 0. The response scale ranged from $1(0-10$ books) to 6 (more than 500 books).

\subsection{Analytical strategy}

\subsubsection{Structural equation analysis}

In a first step, we screened all central variables for outliers, but did not identify values deviating more than three standard deviations from the mean. An exception was the measure of reading strategy knowledge which showed eight small outliers. We considered these outliers as realistic and largely due to the limited variance of reading strategy knowledge overall. Due to these results, we decided to use robust 
maximum likelihood (MLR; used in confirmatory factor analyses of PI and reading comprehension) and weighted-least square parameter estimates (WLSMV; used in all models including ordinal variables) to control for outliers and nonnormality (Brown, 2006; Muthén \& Muthén, 1998-2012).

Hypotheses were tested using structural equation modelling by means of Mplus 7.3 (Muthén \& Muthén, 1998-2012). In line with the conceptualization of the construct and preliminary factor-analytic work (Wollny et al., 2016), PI was modelled as a second-order factor with first-order factors each representing one subscale of the questionnaire. Reading strategy knowledge was modelled as a one-factor model. Because the reading comprehension measures comprised too many items for a stable factor solution, we used the odd-even parceling method to obtain a model of reading comprehension at Time 1 and at Time 2 that is more parsimonious and less affected by random error (e.g., Matsunaga, 2008). Confirmatory factor analyses yielded adequate model fits for all measurement models.

Since the students were nested in school classes, we computed intraclass correlation coefficients (ICC) for PI, reading strategy knowledge, and reading comprehension with school class as cluster variable in order to check the level of non-independence. ICCs for reading comprehension were .17 and .14 for Time 1 and 2, respectively, whereas PI and reading strategy knowledge showed smaller ICCs (between .03 and .04). Thus, a substantial amount of variance in reading comprehension could be explained by the class membership of students. To take this non-independence of observations into account, we controlled for the nested nature of the data by using the Mplus syntax TYPE $=$ COMPLEX.

Reading strategy knowledge and the number of books per household were measured with an ordinal answering scale. Therefore, we used a means and variances adjusted weighted least squares estimator (WLSMV) in all models that included these variables. Models were evaluated as acceptable if they met the following cut-off criteria: the comparative fit index (CFI) and Tucker-Lewis index (TLI) above .95 , the root-mean-square-error of approximation (RMSEA) below .08, and the standardized rootmean-square residual (SRMR) below .05 (Hu \& Bentler, 1999; Schermelleh-Engel, Moosbrugger, \& Müller, 2003). We also report the $\chi^{2}$-statistic, which, however, was not used as criterion due to its oversensitivity to large sample sizes (Schermelleh-Engel et al., 2003).

\subsubsection{Measurement invariance}

Prior to testing differences between measurement waves/groups, the measurement models have to be tested for invariance. Models must demonstrate at least equivalent factor loadings across time/groups (metric invariance; Vandenberg \& Lance, 2000). We therefore analysed measurement invariance across time for PI (because it was assessed by the same questionnaire at Time 1 and Time 2). We did not test longitudinal measurement invariance of reading comprehension, because different measures of reading comprehension were used at Time 1 and 2 . We further tested measurement invariance across groups for PI, reading strategy knowledge, and reading comprehension. In doing so, we applied a stepwise procedure. First, we fixed the factor structure (configural invariance), then factor loadings (metric invariance), then intercepts (scalar invariance), and then residual variances (strict invariance) to be equal across time points/groups (Vandenberg \& Lance, 2000). The level of measurement invariance was identified by comparing the model fit at every step of invariance to that of the preceding step of invariance. To this end, we tested measures of reading comprehension at Time 1 and Time 2 together in an integrated model. This provided the obligatory degrees of freedom for testing all steps of measurement invariance. Measures of PI and reading strategy knowledge were tested separately for measurement invariance. As indicators for substantial reduction of model fit, we used the cut-off rules suggested for CFI, RMSEA, and SRMR by Chen $(2007 ; \Delta$ CFI $\geq-.010$, supplemented by $\triangle$ RMSEA $\geq .015$ or $\Delta$ SRMR $\geq-.010)$.

\subsubsection{Missing data}

At Time 2, 1,009 students participated again (dropout rate $=6.3 \%$ ). Moreover, 892 parents participated at Time 0, 803 participated at Time 1, and 709 at Time 2 (dropout rate $\mathrm{t}_{0}-\mathrm{t}_{1}=10.0 \% ; \mathrm{t}_{1}-\mathrm{t}_{2}=$ 
$11.7 \%$ ). Note that the only measure obtained at Time 0 was the number of books at home rated by parents. Beyond these participation and attrition rates, all variables showed less than $4 \%$ missing values. If possible, we used the Full Information Maximum Likelihood (FIML) to account for missing data. However, when models included ordinal variables (i.e., reading strategy knowledge), we used the WLSMV algorithm as the default estimator of Mplus. If control variables are included, the WLSMV estimator handles missing values by a mixture of FIML and pair-wise procedure (Newsom, 2015).

\section{Results}

\subsection{Descriptive results and correlations}

Table 1 presents means and standard deviations of continuous variables for the total sample and separated by group. We conducted several two-tailed $t$-tests to examine potential group effects on the continuous variables. As could be expected, students of Group 2 (older students) had a significantly higher mean level of reading comprehension at Time 1 and 2 (Table 1). Somewhat unexpected, older students showed higher cognitive ability than younger students, although the scores were normed by age ( $T$ values). Mean levels of PI did not differ between groups, which is consistent with previous findings on older students (Study 1 in Wollny et al., 2016). Because socioeconomic status and reading strategy knowledge were measured on an ordinal scale, we report their frequencies instead. Parents reported to have zero to ten books $(0.6 \%), 11$ to 25 books $(2.5 \%), 26$ to 100 books $(21.1 \%), 101$ to 200 books (21.5\%), 201 to 500 books $(34.4 \%)$, or more than 500 books $(18.4 \%)$ in their household. Students reported on average that they do not know any reading strategy $(5 \%)$, that they have heard of any reading strategy $(34.4 \%)$, or that they know how to apply any strategy (60.5\%). Groups did not differ in socioeconomic status, $\chi^{2}(5)=4.01, p=.557$. However, as could be expected, students in Group 2 reported higher reading strategy knowledge than students in Group $1, \chi^{2}(17)=38.28, p=.002$.

Table 2 presents bivariate correlations between all study variables and control variables. We also controlled for group and computed partial correlations, which were similar to bivariate correlations (Table 2).

\subsection{Measurement invariance}

The results of testing measurement invariance across time points (Time 1 vs. Time 2) and groups (Group 1 vs. Group 2) are displayed in the appendix (Table A.1). With respect to measurement invariance across time, we found that the model of PI was strictly invariant. With respect to differences in measurement models across groups, the measurement models of reading strategy knowledge and of reading comprehension proved strict measurement invariance. In case of PI, the second-order factor model did not provide the necessary degrees of freedom to test configural invariance in a conventional sense. However, van de Schoot, Lugtig, and Hox (2012) proposed that configural measurement invariance is also given if the model is found to be valid independently in each group. Due to the fact that PI showed an adequate and comparable model fit in both groups (Group 1: $\chi^{2}(111)=209.82, p<.001, \mathrm{CFI}=.964$, RMSEA $=.045 ;$ SRMR $=.050$; Group 2: $\chi^{2}(111)=260.22, p<.001$, CFI $=.955$, RMSEA $=.055$, SRMR $=.049)$, we concluded that PI was configural invariant across groups. We then proceeded with the regular way of testing measurement invariance and found that fixing the intercepts to be equal produced an intolerable deterioration of model fit $(\triangle \mathrm{CFI} \geq-.010$, supplemented by $\triangle \mathrm{RMSEA} \geq .015$ or $\triangle \mathrm{SRMR} \geq$ .010; Chen, 2007). As a consequence, with respect to groups, we could only establish metric invariance for PI. 
Table 1

Mean values, standard deviations, and group differences of continuous variables

\begin{tabular}{|c|c|c|c|c|c|c|c|c|c|c|}
\hline \multirow[b]{2}{*}{ Variable } & \multicolumn{4}{|c|}{ Total sample } & \multicolumn{2}{|c|}{ Group 1} & \multicolumn{2}{|c|}{ Group 2} & \multirow{2}{*}{$\begin{array}{c}\begin{array}{c}\text { Two-tailed } \\
t \text {-test }\end{array} \\
t(d f) \\
\end{array}$} & \multirow{2}{*}{$\begin{array}{c}\begin{array}{c}\text { Effect } \\
\text { size }\end{array} \\
d \\
\end{array}$} \\
\hline & $N$ & Range & $M$ & $S D$ & $M$ & $S D$ & $M$ & $S D$ & & \\
\hline $\begin{array}{l}\text { T1 Cognitive } \\
\text { ability }\end{array}$ & 1098 & $27-80$ & 54.63 & 8.95 & 54.09 & 8.95 & 55.16 & 8.91 & $-1.98 *(1096)$ & .12 \\
\hline $\begin{array}{l}\text { T1 Personal } \\
\text { initiative }\end{array}$ & 803 & $1-5$ & 3.05 & 0.77 & 3.02 & 0.77 & 3.08 & 0.77 & $-1.00(801)$ & .06 \\
\hline $\begin{array}{l}\text { T2 Personal } \\
\text { initiative }\end{array}$ & 709 & $1-5$ & 3.10 & 0.82 & 3.05 & 0.80 & 3.14 & 0.83 & $-1.50(707)$ & .11 \\
\hline $\begin{array}{l}\text { T1 Reading } \\
\text { comprehension } \\
\text { T2 Reading }\end{array}$ & 1102 & $0-10$ & 6.14 & 2.52 & 5.41 & 2.48 & 6.86 & 2.35 & $-9.95 * * *(1100)$ & .60 \\
\hline comprehension & 1003 & $0-10$ & 4.93 & 2.43 & 4.50 & 2.37 & 5.35 & 2.42 & $-5.62 * * *(1001)$ & .35 \\
\hline
\end{tabular}

Note. This table does not include descriptive statistics of socioeconomic status and reading strategy knowledge because these variables were measured on an ordinal scale (instead, see frequencies and chi-squared tests reported in the descriptive results section). Group 1 refers to students in $3^{\text {rd }}$ grade at Time 1 and $5^{\text {th }}$ grade at Time 2 . Group 2 refers to students in $4^{\text {th }}$ grade at Time 1 and $6^{\text {th }}$ grade at Time 2 .

$* p<.05 . * * p .01 . * * * p<.001$.

Table 2

Bivariate and partial correlations among study variables and control measures (total sample)

\begin{tabular}{|c|c|c|c|c|c|c|c|c|c|}
\hline Variable & 1 & $2^{\mathrm{a}}$ & $3^{\mathrm{b}}$ & 4 & 5 & 6 & $7^{\mathrm{b}}$ & 8 & 9 \\
\hline Group & -- & -- & -- & -- & -- & -- & -- & -- & -- \\
\hline T1 Gender ${ }^{\mathrm{a}}$ & .03 & -- & $.07 *$ & $-.20 * * *$ & $-.09 *$ & $-.17 * * *$ & -.04 & $-.07 *$ & $.06 *$ \\
\hline T0 SES ${ }^{b}$ & .00 & $.07 *$ & -- & .06 & $.14 * * *$ & $.14 * * *$ & $.07 *$ & $.27 * * *$ & $.33 * * *$ \\
\hline T1 Cognitive ability & $.06^{*}$ & $-.19 * * *$ & .06 & -- & $.19 * * *$ & $.17 * * *$ & $.07 *$ & $.33 * * *$ & $.15^{* * *}$ \\
\hline T1 Personal initiative & .04 & $-.09 *$ & $.14 * *$ & $.19 * * *$ & -- & $.67 * * *$ & $.16 * * *$ & $.21 * * *$ & $.22 * * *$ \\
\hline T2 Personal initiative & .06 & $-.17 * * *$ & $.14 * *$ & $.17 * * *$ & $.67 * * *$ & -- & $.21 * * *$ & $.28 * * *$ & $.25 * * *$ \\
\hline T2 Strategy knowledge ${ }^{b}$ & $.12 * * *$ & -.04 & $.07 *$ & $.08^{*}$ & $.17 * * *$ & $.22 * * *$ & -- & $.20 * * *$ & $.16^{* * *}$ \\
\hline T1 Reading comprehension & $.29 * * *$ & -.06 & $.26 * * *$ & $.33 * * *$ & $.21 * * *$ & $.28 * * *$ & $.22 * * *$ & -- & $.53 * * *$ \\
\hline T2 Reading comprehension & $.18 * * *$ & $.07 *$ & $.32 * * *$ & $.16 * * *$ & $.22 * * *$ & $.26 * * *$ & $.18 * * *$ & $.55 * * *$ & -- \\
\hline
\end{tabular}

Note. $N=626-1099$. SES $=$ socioeconomic status. Bivariate correlations are shown below the diagonal, partial correlations controlled for group are shown above the diagonal.

${ }^{a}$ female $=1$, male $=2$.

${ }^{\mathrm{b}} \mathrm{We}$ computed spearman rank-based correlations for ordinal variables.

$* p<.05 . * * p<.01 . * * p<.001$. 


\subsection{Group effects in structural equation modelling}

After establishing measurement invariance, the hypothesized model (see Figure 1) was tested for moderating effects by group. To this end, we used a multiple group approach with grade level as a group factor. This group-specific mediation model revealed an acceptable model fit. In the next step, we fixed all directed paths to be equal across groups and compared the resulting model fit with the unconstrained model. This yielded a non-significant $\chi^{2}$ difference between the models, $\Delta \chi^{2}(22)=17.17, p=.532$. However, this test of overall differences has low sensitivity to differences in single paths. We therefore tested every single directed path for significance and found significant group differences in the paths from Time 1 reading comprehension to Time 2 reading comprehension $\left(\Delta \chi^{2}=11.76^{* * *}\right)$, Time 1 reading comprehension to Time 2 PI $\left(\Delta \chi^{2}=12.75^{* * *}\right)$, and Time 2 strategy knowledge to Time 2 reading comprehension $\left(\Delta \chi^{2}=5.03^{*}\right)$. As can be seen in Figure 2, the last two of these paths reached significance in Group 2 but not in Group 1. Moreover, the impact of Time 1 reading comprehension on Time 2 reading comprehension was found to be higher in Group 1 than in Group 2. Finally, we also found a range of group differences with respect to effects by control variables (see Table A.2 in the appendix). Together, these differences indicate that the group status - in other words, whether students were in the lower or higher grade - had an essential impact on the estimated structural relations and the hypothesized mediation model. Thus, the two groups differed considerably in their developmental dynamics. As a result, we freed all paths that varied significantly across groups. The resulting model exhibited a good model fit with the data, $\chi^{2}(945)=1072.23, p=.002, \mathrm{CFI}=.972, \mathrm{RMSEA}=.016$.

\subsection{Relations among personal initiative, reading strategy knowledge, and reading comprehension}

After the establishment of a parsimonious model that took group effects into account, we tested the hypotheses. As depicted in Figure 2, the autoregressive effects of PI and the effect of Time 1 reading comprehension on Time 2 reading comprehension were high in both groups. In terms of our hypothesized mediation model, we found that Time 1 PI positively predicted Time 2 reading strategy knowledge in both groups. However, only in the group from fourth to sixth grade reading strategy knowledge significantly contributed to Time 2 reading comprehension. Thus, we could only test the hypothesized mediation process in Group 2. Using the Monte Carlo method (Hayes \& Scharkow, 2013), we found a significant indirect effect of PI on reading comprehension mediated by reading strategy knowledge in Group $2, \beta=.02, p<.05,95 \%$ CI $[.009, .036]$. Furthermore, Time 1 PI directly contributed to Time 2 reading comprehension in both groups. Thus, the observed indirect effect from fourth to sixth grade indicated partial mediation.

Our model also included a number of paths that were not part of our mediation hypothesis. As we had expected, Time 1 reading comprehension positively predicted reading strategy knowledge at Time 2 in both groups. By testing bidirectional relations, we further observed that Time 1 reading comprehension significantly predicted Time 2 PI in Group 2.

\section{Discussion}

Previous research has put little emphasis on the role of PI in the prediction of reading comprehension. This study aimed at closing this gap in literature by examining the role of PI in predicting reading comprehension in two groups of elementary students and by investigating the underlying mechanism of this proposed relation. In particular, we hypothesized a mediational process in which PI is positively related to reading comprehension via the development of reading strategy knowledge. In support of Hypothesis 1, we found that PI directly contributed to the development of reading strategy knowledge and 
reading comprehension from third to fifth and fourth to sixth grade. In terms of the proposed mediation (Hypothesis 2), the results differed by grade level.

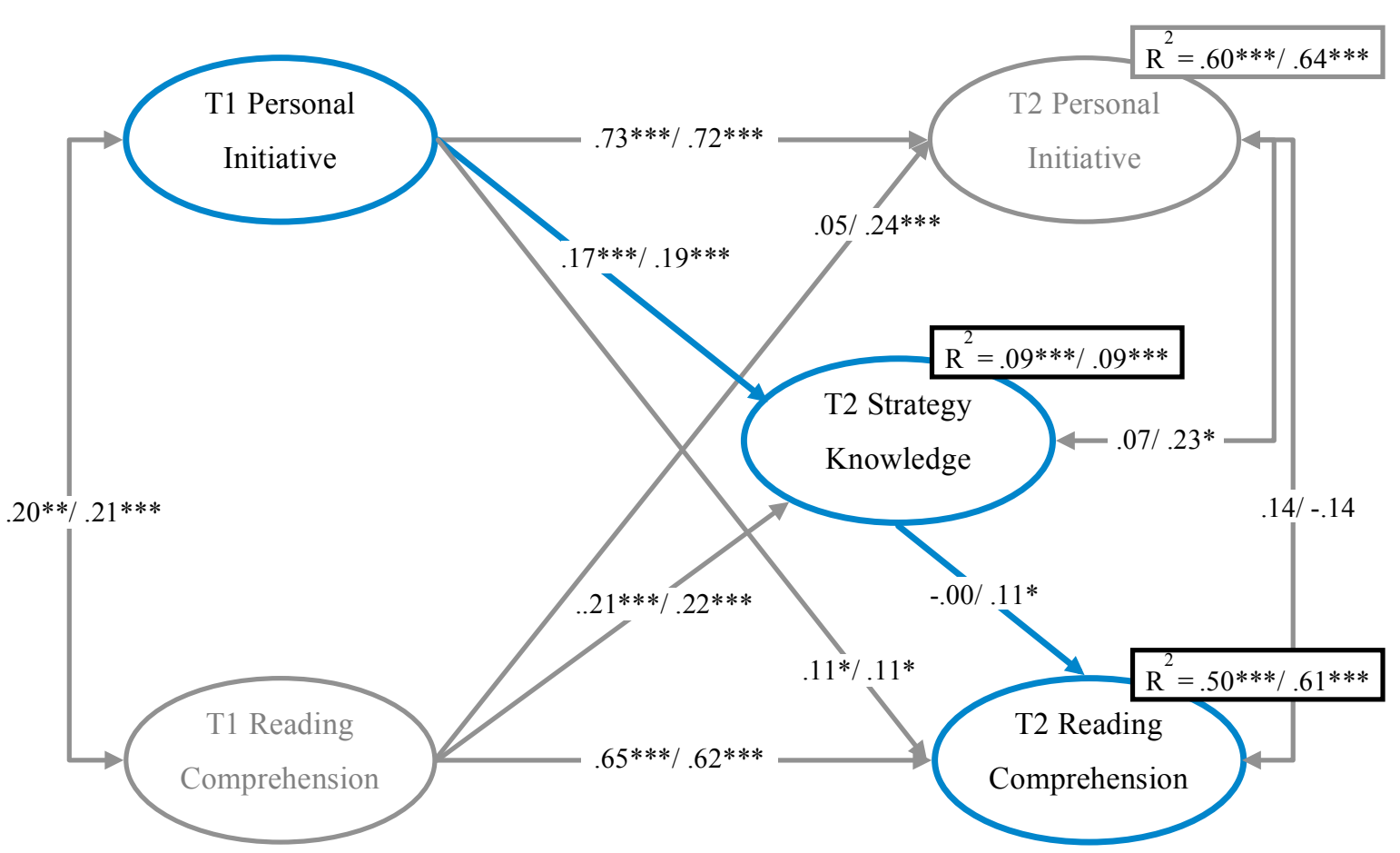

Figure 2. Multiple group structural equation model. Only standardized path coefficients are displayed.

The first coefficient refers to Group 1 and the second coefficient refers to Group 2. Group 1 refers to students in $3^{\text {rd }}$ grade at Time 1 and $5^{\text {th }}$ grade at Time 2 . Group 2 refers to students in $4^{\text {th }}$ grade at Time 1 and $6^{\text {th }}$ grade at Time 2. Directed paths were constrained to be equal except the paths from T2 reading strategy knowledge to $\mathrm{T} 2$ reading comprehension, T1 reading comprehension to T2 PI, and T1 cognitive ability to T2 PI. For clarity, residual variances, indicators, and effects of control variables (see Appendix, Table A.2) are not shown here.

$* p<.05 . * * p .01 . * * * p<.001$.

\subsection{Personal initiative and reading strategy knowledge}

It is one of our noteworthy results that PI predicted reading strategy knowledge consistently among two groups of students even though we controlled for previous reading comprehension and for several covariates. This finding provides rare evidence for a positive longitudinal relation between a domainunspecific self-regulatory construct, i.e., PI, and the development of specific metacognitive knowledge, i.e., reading strategy knowledge. It further complements the view of self-regulated learning as a primarily domain-specific construct (e.g., Massey, 2009) and emphasizes the interconnectedness of domain-unspecific with domain-specific self-regulatory behaviour.

Moreover, scholars repeatedly emphasized that metacognitive knowledge relies considerably on direct instructions through teaching (e.g., Borkowski et al., 2000; Pintrich, 2002). In agreement with this, class membership represented an important determinant of reading comprehension in the present sample. Therefore, in the analyses, we took into account that students were nested in classes. Even when taking these systematic differences based on instruction into account, PI remained a significant predictor. Thus, although 


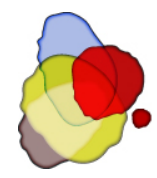

the instruction of reading strategy knowledge is firmly anchored in German curricula, the present findings suggest that the acquisition of appropriate reading strategy knowledge depends to some extent also on the proactive efforts of an individual. This by no means indicates that school instruction is dispensable in the acquisition of reading strategy knowledge. Instead, it highlights that students might differ in how much they apply, expand, and transfer this knowledge on their own initiative.

\subsection{Reading strategy knowledge and reading comprehension}

When testing the mediation hypothesis, the results only provided partial support for the proposed link between reading strategy knowledge and reading comprehension. With regard to sixth grade students, we found a positive effect of reading strategy knowledge on reading comprehension. In fifth grade students, however, reading strategy knowledge failed to show any substantial association with reading comprehension. Two reasons could account for this finding. First, it is possible that fifth grade students might have had difficulties in transferring their reading strategy knowledge into efficient reading activities. This is referred to as utilization deficiency. This deficiency describes a developmental stage, in which students correctly know how to use reading strategies but have not automated them to such an extent that their reading comprehension benefits notably from their application (Miller, 1990). According to the curriculum of the federal state of Brandenburg, only from fifth grade onwards the instruction of reading strategies is systematically extended to a larger range of school subjects (Ministery of education of the federal state of Brandenburg, 2004). Thus, fifth grade students might have just been beginning to extend their reading strategy knowledge to other school subjects and might simply have had less practice in applying reading strategies than sixth grade students.

Second, we found that the measure of reading strategy knowledge was less valid in the sample of fifth grade students than in the sample of sixth grade students. By asking about their knowledge of a nonexisting reading strategy (see 2.2.4.), we observed that fifth grade students more frequently reported to be familiar with this strategy than sixth grade students. This is in accordance with findings that younger children's metacognitive self-reports are prone to overestimation (e.g., Ferreira, Simão, \& da Silva, 2015). However, regardless of the underlying mechanism (i.e., utilization deficiency or overestimation), our findings complement results of previous studies in which reading strategy knowledge seemed to be more highly related with reading performance at higher grade levels (e.g., Kolić-Vehovec et al., 2014; van Kraayenoord \& Schneider, 1999).

\subsection{Personal initiative and reading comprehension}

The hypothesized indirect effect from PI on reading comprehension via reading strategy knowledge was supported for more advanced students (i.e., students who moved from fourth to sixth grade from Time 1 to 2), but not for the less advanced group of students (i.e., students who moved from third to fifth grade). Thus, with regard to older elementary students, a general tendency to show PI seems to lead to the development of reading strategy knowledge, which in turn promotes reading development. These findings highlight the potential of PI in promoting learning processes (such as reading development), as emphasized in theories of self-regulated learning (e.g., Zimmerman, 2002). They further represent a step forward in supporting theories that propose a complex interconnection between a person's relatively stable selfregulatory tendencies (e.g., PI), domain-specific strategic behaviour (e.g., development of reading strategy knowledge), and domain-specific academic success (e.g., reading comprehension; e.g., Boekaerts, 1999; Borkowski et al., 2000; Efklides, 2011).

It is important to note, however, that the effect size of the observed mediation was small. Moreover, in both groups we also found a direct contribution of PI on reading comprehension that was not mediated by reading strategy knowledge. This might be due to methodological reasons. For example, students might have reported that they know a certain strategy, but might have failed to apply the strategy during the actual 
reading task (Bjorklund \& Douglas, 1997; Flavell, 1970). Moreover, variance of strategy knowledge was comparatively low (see Table 1) and the questionnaire did not assess the entire range of potentially useful reading strategies (see Mokhtari \& Reichard, 2002). Thus, students might have used alternative reading strategies, which were simply not assessed in the present study and were thus not reported by the students.

However, the direct effect of PI on reading comprehension might also indicate that other mediating mechanisms exist beyond the use of and knowledge about reading strategies. For example, students with a high level of PI tend to be learning-oriented (Wollny et al., 2016) and therefore might simply read more, prefer to read a larger variety of text genres, be more engaged in reading lessons, and choose more challenging text material than students lower on PI.

Finally, there was also a reversed long-term effect of reading comprehension on PI in the group of sixth grade students. This effect was not surprising considering that adequate reading performance promotes the development of academic self-concepts (e.g., Chapman, Tunmer, \& Prochnow, 2000) and might intensify a potential big fish little pond effect. Thus, good readers likely develop strong internal control and selfefficacy beliefs, which in turn relate to higher scores of PI in children (Wollny et al., 2016). Because the developmental shift from "learning to read" to "reading to learn" happens around fourth grade (Rupley \& Willson, 1996), we assume that the mutually supportive mechanisms between PI and reading comprehension take some time to unfold. This might explain why we found this reversed effect only in the group of sixth grade students.

\subsection{Limitations and future research}

There are some limitations to bear in mind when interpreting the results from the present study. First of all, we investigated the hypothesized mediational process by using only two measurement points. Thus, the observed associations between reading strategy knowledge and reading comprehension were only crosssectional. Additional research is therefore necessary to replicate our findings within a three-wave longitudinal study.

Second, because this study was conducted within the scope of a larger longitudinal project, we had to use relatively short measures of reading strategy knowledge and reading comprehension. As a result, the variance of our measure of reading strategy knowledge was low, which may have reduced the magnitude of the observed mediational relations. Future studies might benefit from using measures that cover a larger variety of reading strategies (e.g., Mokhtari \& Reichard, 2002; Wernke et al., 2011). This requires also the use of more extended assessments of reading comprehension, such as the use of longer texts and different text types. Because PI is a domain-unspecific construct, it might show similar effects across text types. On the other hand, the effects of PI might also be contingent on students' preferences for particular text types (e.g., fiction vs. non-fiction) or might be particularly helpful in reading texts that require many proactive efforts (e.g., hypertexts).

Third, the measures of PI and reading comprehension demonstrated a high stability over time leaving little variance to be explained by predictors. The control of stabilities therefore likely reduced the magnitude of observed effects of PI and reading strategy knowledge on the development of reading comprehension (as well as of reading comprehension on the development of PI). However, although the observed effect sizes appeared to be small, they are not trivial in light of the conservative longitudinal approach of this study (e.g., Adachi \& Willoughby, 2015).

Fourth, this study focused entirely on intrapersonal predictors of reading comprehension leaving the question open as to how predictors beyond individual characteristics, such as the quality of instruction or the level of classroom performance, affect these intrapersonal processes.

Finally, we examined PI by using parent ratings. Parents observe their child's PI in a range of contexts that are not limited to the academic learning environment. Thus, parent ratings of PI represent a broad measure of PI, which may have had a diminishing effect on the relations found in the present study. 
Therefore, in future studies, researchers might consider using self-reports and observational measures of PI and combining them within a multi-method approach.

\section{Conclusions}

Results from the present study are unique in that they document the contribution of students' PI on the development of both reading strategy knowledge and reading comprehension. These findings underline the potential relevance of PI as a contributor to academic success. It should be noted, however, that we found only limited support for the proposed mediation. This limitation aside, the results from the present study suggest that efforts to foster PI might have positive long-term effects on reading comprehension. In adults, emerging evidence indicates that PI is amenable to training and can be increased by higher job autonomy and job control (e.g., Glaub, Frese, Fischer, \& Hoppe, 2014; Li, Fay, Frese, Harms, \& Gao, 2014). Likewise, PI relates to self-efficacy and internal control orientations in children (Wollny et al., 2016). Therefore, teaching practices should be aimed at encouraging students' sense of responsibility for their own learning progress. This can be achieved by providing open-ended and student-centered learning environments (e.g., Paris \& Paris, 2001; Turner, 1995). Thus, students should be encouraged to choose their own learning tasks, to seek solutions on their own, and to develop and express their own learning goals (e.g., Duke \& Pearson, 2002; Stefanou, Perencevich, DiCintio, \& Turner, 2004).

\section{Keypoints}

- Developing reading comprehension requires personal initiative.

- We used longitudinal structural equation modelling with data on 1,102 elementary students.

- Personal initiative predicted reading strategy knowledge and reading comprehension.

- Strategy knowledge mediated the effects of personal initiative from Grade 4 to 6.

\section{Acknowledgements}

This research was funded by the German Research Foundation [DFG; grant number 1668/1].

\section{References}

Adachi, P., \& Willoughby, T. (2015). Interpreting effect sizes when controlling for stability effects in longitudinal autoregressive models: Implications for psychological science. European Journal of Developmental Psychology, 12, 116-128. doi:10.1080/17405629.2014.963549

Artelt, C., Naumann, J., \& Schneider, W. (2010). Lesemotivation und Lernstrategien [Reading motivation and reading strategies]. In E. Klieme, C. Artelt, J. Hartig, N. Jude, O. Köller, M. Prenzel, W. Schneider \& P. Stanat (Eds.), PISA 2009. Bilanz nach einem Jahrzehnt (pp. 73-112). Münster, Germany: Waxmann.

Bäuerlein, K., Lenhard, W., \& Schneider, W. (2012). Lesetestbatterie für die Klassenstufen 6-7 [Reading test battery for 6th- and 7th-graders]. Göttingen, Germany: Hogrefe.

Best, J. R., Miller, P. H., \& Jones, L. L. (2009). Executive functions after age 5: Changes and correlates. Developmental Review, 29, 180-200. doi: 10.1016/j.dr.2009.05.002 
Birgisdóttir, F., Gestsdóttir, S., \& Thorsdóttir, F. (2015). The role of behavioral self-regulation in learning to read: A 2-year longitudinal study of Icelandic preschool children. Early Education and Development, 26, 807-828. doi: 10.1080/10409289.2015.1003505

Bjorklund, D. F., \& Douglas, R. N. (1997). The development of memory strategies. In N. Cowan \& N. Cowan (Eds.), The development of memory in childhood (pp. 201-246). Hove, England: Psychology Press/Erlbaum (UK) Taylor \& Francis.

Boekaerts, M. (1999). Self-regulated learning: Where we are today. International Journal of Educational Research, 31, 445-457. doi: 10.1016/S0883-0355(99)00014-2

Borkowski, J. G., Chan, L. K., \& Muthukrishna, N. (2000). A process-oriented model of metacognition: Links between motivation and executive functioning. In G. Schraw \& J. Impara (Eds.), Issues in the measurement of metacognition (pp. 1-41). Lincoln, NB, US: University of Nebraska Press.

Botsas, G., \& Padeliadu, S. (2003). Goal orientation and reading comprehension strategy use among students with and without reading difficulties. International Journal of Educational Research, 39, 477-495. doi: 10.1016/j.ijer.2004.06.010

Bowey, J. A. (2005). Predicting individual differences in learning to read. In M. J. Snowling, C. Hulme, M. J. Snowling \& C. Hulme (Eds.), The science of reading: A handbook. (pp. 155-172). Malden, MA, US: Blackwell Publishing.

Brown, T. A. (2006). Confirmatory factor analysis for applied research. New York, NY, US: Guilford Press.

Cain, K., Oakhill, J., \& Bryant, P. (2004). Children's reading comprehension ability: Concurrent prediction by working memory, verbal ability, and component skills. Journal of Educational Psychology, 96, 31 42. doi: $10.1037 / 0022-0663.96 .1 .31$

Cantrell, S. C., \& Carter, J. C. (2009). Relationships among learner characteristics and adolescents' perceptions about reading strategy use. Reading Psychology, 30, 195-224. doi: $10.1080 / 02702710802275397$

Caraway, K., Tucker, C. M., Reinke, W. M., \& Hall, C. (2003). Self-efficacy, goal orientation and fear of failure as predictors of school engagement in high school students. Psychology in the Schools, 40, 417 427. doi: $10.1002 /$ pits. 10092

Chapman, J. W., Tunmer, W. E., \& Prochnow, J. E. (2000). Early reading-related skills and performance, reading self-concept, and the development of academic self-concept: A longitudinal study. Journal of Educational Psychology, 92, 703-708. doi: 10.1037/0022-0663.92.4.703

Chen, F. F. (2007). Sensitivity of goodness of fit indexes to lack of measurement invariance. Structural Equation Modeling, 14, 464-504. doi: 10.1080/10705510701301834

Chiu, M. M., \& McBride-Chang, C. (2006). Gender, context, and reading: A comparison of students in 43 countries. Scientific Studies of Reading, 10, 331-362. doi: 10.1207/s1532799xssr1004_1

Denton, C. A., Wolters, C. A., York, M. J., Swanson, E., Kulesz, P. A., \& Francis, D. J. (2015). Adolescents' use of reading comprehension strategies: Differences related to reading proficiency, grade level, and gender. Learning and Individual Differences, 37, 81-95. doi: 10.1016/j.lindif.2014.11.016

Dermitzaki, I., Andreou, G., \& Paraskeva, V. (2008). High and low reading comprehension achievers' strategic behaviors and their relation to performance in a reading comprehension situation. Reading Psychology, 29, 471-492. doi: 10.1080/02702710802168519

Dignath, C., Buettner, G., \& Langfeldt, H.-P. (2008). How can primary school students learn self-regulated learning strategies most effectively?: A meta-analysis on self-regulation training programmes. Educational Research Review, 3, 101-129. doi: 10.1016/j.edurev.2008.02.003

DiPerna, J. C., Volpe, R. J., \& Elliott, S. N. (2005). A model of academic enablers and mathematics achievement in the elementary grades. Journal of School Psychology, 43, 379-392. doi:10.1016/j.jsp.2005.09.002

Duke, N. K., \& Carlisle, J. (2011). The development of comprehension. In M. L. Kamil, P. D. Pearson, E. B. Moje \& P. P. Afflerbach (Eds.), Handbook of reading research (Vol. 4, pp. 199-228). New York, NY, US: Routledge. 
Duke, N. K., \& Pearson, P. (2002). Effective practices for developing reading comprehension. In A. E. Farstrup \& S. J. Samuels (Eds.), What research has to say about reading instruction (3rd ed., pp. 205242). Newark, DE, US: International Reading Association.

Efklides, A. (2011). Interactions of metacognition with motivation and affect in self-regulated learning: The MASRL model. Educational Psychologist, 46, 6-25. doi: 10.1080/00461520.2011.538645

Fay, D., \& Frese, M. (2001). The concept of personal initiative: An overview of validity studies. Human Performance, 14, 97-124. doi: 10.1207/S15327043HUP1401_06

Ferreira, P. C., Simão, A. M. V., \& da Silva, A. L. (2015). The unidimensionality and overestimation of metacognitive awareness in children: Validating the CATOM. Anales de Psicología, 31, 890-900. doi: 10.6018/analesps.31.3.184221

Flavell, J. H. (1970). Developmental studies of mediated memory. In H. W. Reese \& L. P. Lipsitt (Eds.), Advances in child development and behavior (Vol. 5, pp. 181-211). New York, NY, US: Academic Press.

Frese, M., \& Fay, D. (2001). Personal initiative: An active performance concept for work in the 21st century. In B. M. Staw \& R. I. Sutton (Eds.), Research in organizational behavior (Vol. 23, pp. 133-187). San Diego, CA, US: Elsevier Academic Press.

Frese, M., Fay, D., Hilburger, T., Leng, K., \& Tag, A. (1997). The concept of personal initiative: Operationalization, reliability and validity of two German samples. Journal of Occupational and Organizational Psychology, 70, 139-161. doi: 10.1111/j.2044-8325.1997.tb00639.x

Gadermann, A. M., Guhn, M., \& Zumbo, B. D. (2012). Estimating ordinal reliability for Likert-type and ordinal item response data: A conceptual, empirical, and practical guide. Practical Assessment, Research \& Evaluation, 17, 1-13.

Glaub, M. E., Frese, M., Fischer, S., \& Hoppe, M. (2014). Increasing personal initiative in small business managers or owners leads to entrepreneurial success: A theory-based controlled randomized field intervention for evidence-based management. Academy of Management Learning \& Education, 13, 354-379. doi: 10.5465/amle.2013.0234

Gourgey, A. F. (1998). Metacognition in basic skills instruction. Instructional Science, 26, 81-96. doi: 10.1023/a:1003092414893

Hayes, A. F., \& Scharkow, M. (2013). The relative trustworthiness of inferential tests of the indirect effect in statistical mediation analysis: Does method really matter? Psychological Science, 24, 1918-1927. doi: $10.1177 / 0956797613480187$

Hirvonen, R., Georgiou, G. K., Lerkkanen, M.-K., Aunola, K., \& Nurmi, J.-E. (2010). Task-focused behaviour and literacy development: A reciprocal relationship. Journal of Research in Reading, 33, 302-319. doi:10.1111/j.1467-9817.2009.01415.x

Horner, S. L., \& Shwery, C. S. (2002). Becoming an engaged, self-regulated reader. Theory into Practice, 41, 102-109. doi: 10.1207/s15430421tip4102_6

$\mathrm{Hu}$, L.-t., \& Bentler, P. M. (1999). Cutoff criteria for fit indexes in covariance structure analysis: Conventional criteria versus new alternatives. Structural Equation Modeling: A Multidisciplinary Journal, 6, 1-55. doi: 10.1080/10705519909540118

Janke, B., \& Hasselhorn, M. (2008). Frühes Schulalter [Early school age]. In M. Hasselhorn \& R. K. Silbereisen (Eds.), Theorie und Forschung, Enzyklopädie der Psychologie, Serie Entwicklungspsychologie (Vol. 7, pp. 413-447). Göttingen: Hogrefe.

Jimerson, S. R., Campos, E., \& Greif, J. L. (2003). Toward an understanding of definitions and measures of school engagement and related terms. California School Psychologist, 8, 7-27. doi: 10.1007/bf03340893

Kenny, D. A. (1975). Cross-lagged panel correlation: A test for spuriousness. Psychological Bulletin, 82, 887-903. doi: 10.1037/0033-2909.82.6.887

Kintsch, W. (1998). Comprehension: A paradigm for cognition. New York, NY, US: Cambridge University Press.

Kletzien, S. B. (1991). Strategy use by good and poor comprehenders reading expository text of differing levels. Reading Research Quarterly, 26, 67-86. doi: 10.2307/747732 
Kolić-Vehovec, S., Zubković, B. R., \& Pahljina-Reinić, R. (2014). Development of metacognitive knowledge of reading strategies and attitudes toward reading in early adolescence: The effect on reading comprehension. Psihologijske Teme, 23, 77-98. doi: 159.946.4.072-053.6

Kolić-Vehovec, S., \& Bajsanski, I. (2001). Children's metacognition as predictor of reading comprehension at different developmental levels. In G. Shiel \& U. Ni Dhalaigh (Eds.), Other ways of seeing: Diversity in language and literacy. Dublin, Ireland: Readin Association of Ireland.

Lenhard, W., \& Schneider, W. (2006). Leseverständnistest für Erst- bis Sechstklässler [Reading comprehension test for 1st- to 6th-graders]. Göttingen, Germany: Hogrefe.

Li, W.-D., Fay, D., Frese, M., Harms, P. D., \& Gao, X. Y. (2014). Reciprocal relationship between proactive personality and work characteristics: A latent change score approach. Journal of Applied Psychology, 99, 948-965. doi: 10.1037/a0036169

Little, T. D., Preacher, K. J., Selig, J. P., \& Card, N. A. (2007). New developments in latent variable panel analyses of longitudinal data. International Journal of Behavioral Development, 31, 357-365. doi: $10.1177 / 0165025407077757$

Lompscher, J. (1995). Erfassung von Lernstrategien mittels Fragebogen [Questionnaire for the assessment of learning strategies]. Lern-und Lehrforschung, 10, 80-136.

Massey, D. D. (2009). Self-regulated comprehension. In S. E. Israel \& G. G. Duffy (Eds.), Handbook of research on reading comprehension (pp. 389-399). New York, NY, US: Routledge.

Matsunaga, M. (2008). Item parceling in structural equation modeling: A primer. Communication Methods and Measures, 2, 260-293. doi:10.1080/19312450802458935

McClelland, M. M., \& Cameron, C. E. (2011). Self-regulation and academic achievement in elementary school children. New Directions for Child and Adolescent Development, 2011, 29-44. doi: 10.1002/cd.302.

McKeachie, W. J. (1987). Cognitive skills and their transfer: Discussion. International Journal of Educational Research, 11, 707-712. doi: 10.1016/0883-0355(87)90010-3

Miller, P. H. (1990). The development of strategies of selective attention. In D. F. Bjorklund \& D. F. Bjorklund (Eds.), Children's strategies: Contemporary views of cognitive development. (pp. 157-184). Hillsdale, England: Lawrence Erlbaum Associates, Inc.

Ministery of education of the federal state of Brandenburg. (2004). Rahmenlehrplan Grundschule Deutsch [Curriculum framework for German at elementary school]. Berlin, Germany: Wissenschaft und Technik Verlag.

Mokhtari, K., \& Reichard, C. A. (2002). Assessing students' metacognitive awareness of reading strategies. Journal of Educational Psychology, 94, 249-259. doi: 10.1037/0022-0663.94.2.249

Muthén, L. K., \& Muthén, B. O. (1998-2012). Mplus user's guide. (7 ed.). Los Angeles, CA, US: Muthén \& Muthén.

Myers, M., \& Paris, S. G. (1978). Children's metacognitive knowledge about reading. Journal of Educational Psychology, 70, 680-690. doi:10.1037/0022-0663.70.5.680

Newsom, J. T. (2015). Longitudinal structural equation modeling: A comprehensive introduction. New York, NY, US: Routledge/Taylor \& Francis Group.

Paris, S. G., Hamilton, E. E., Israel, S., \& Duffy, G. (2009). The development of children's reading comprehension. In S. E. Israel \& G. G. Duffy (Eds.), Handbook of research on reading comprehension (pp. 32-53). New York, NY, US: Routledge.

Paris, S. G., Lipson, M. Y., \& Wixson, K. K. (1983). Becoming a strategic reader. Contemporary Educational Psychology, 8, 293-316. doi: 10.1016/0361-476X(83)90018-8

Paris, S. G., \& Paris, A. H. (2001). Classroom applications of research on self-regulated learning. Educational Psychologist, 36, 89-101. doi: 10.1207/S15326985EP3602_4

Petermann, F., \& Petermann, U. (2008). Hamburg-Wechsler-Intelligenztest für Kinder - IV [Wechsler intelligence scale for children - German version]. Bern, Switzerland: Huber.

Pintrich, P. R. (1991). A manual for the use of the Motivated Strategies for Learning Questionnaire (MSLQ). Ann Arbor, MI, US: School of Education, University of Michigan. 


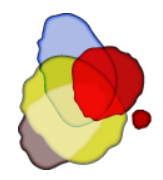

Pintrich, P. R. (2002). The role of metacognitive knowledge in learning, teaching, and assessing. Theory into Practice, 41, 219-225. doi: 10.1207/s15430421 tip4104_3

Pressley, M., \& Afflerbach, P. (1995). Verbal protocols of reading: The nature of constructively responsive reading. Hillsdale, England: Lawrence Erlbaum Associates.

Rupley, W., \& Willson, V. (1996). Content, domain, and word knowledge: Relationship to comprehension of narrative and expository text. Reading and Writing, 8, 419-432. doi: 10.1007/BF00404003

Schermelleh-Engel, K., Moosbrugger, H., \& Müller, H. (2003). Evaluating the fit of structural equation models: Tests of significance and descriptive goodness-of-fit measures. Methods of Psychological Research, 8, 23-74.

Schneider, W. (2010). Metacognition and memory development in childhood and adolescence. In H. S. Waters \& W. Schneider (Eds.), Metacognition, strategy use, and instruction (pp. 54-81). New York, NY, US: Guilford Press.

Schünemann, N., Spörer, N., \& Brunstein, J. C. (2013). Integrating self-regulation in whole-class reciprocal teaching: A moderator-mediator analysis of incremental effects on fifth graders' reading comprehension. Contemporary Educational Psychology, 38, 289-305. doi: 10.1016/j.cedpsych.2013.06.002

Stefanou, C. R., Perencevich, K. C., DiCintio, M., \& Turner, J. C. (2004). Supporting autonomy in the classroom: Ways teachers encourage student decision making and ownership. Educational Psychologist, 39, 97-110. doi: 10.1207/s15326985ep3902_2

Stutz, F., Schaffner, E., \& Schiefele, U. (2016). Relations among reading motivation, reading amount, and reading comprehension in the early elementary grades. Learning and Individual Differences, 45, 101 113. doi: $10.1016 /$ j.lindif.2015.11.022

Turner, J. C. (1995). The influence of classroom contexts on young children's motivation for literacy. Reading Research Quarterly, 30, 410-441. doi: 10.2307/747624

van de Schoot, R., Lugtig, P., \& Hox, J. (2012). A checklist for testing measurement invariance. European Journal of Developmental Psychology, 9, 486-492. doi: 10.1080/17405629.2012.686740

van Kraayenoord, C. E. (2010). The role of metacognition in reading comprehension. In H. Trolldenier, W. Lenhard \& P. Marx (Eds.), Brennpunkte der Gedächntisforschung. Entwicklungs- und pädagogischpsychologische Perspektiven (pp. 277-304). Göttingen, Germany: Hogrefe.

van Kraayenoord, C. E., \& Schneider, W. (1999). Reading achievement, metacognition, reading self-concept and interest: A study of German students in grades 3 and 4. European Journal of Psychology of Education, 14, 305-324. doi: 10.1007/BF03173117

Vandenberg, R. J., \& Lance, C. E. (2000). A review and synthesis of the measurement invariance literature: Suggestions, practices, and recommendations for organizational research. Organizational Research Methods, 3, 4-69. doi: 10.1177/109442810031002

Warner, G. J., Fay, D., Schiefele, U., Stutz, F., \& Wollny, A. (2016). Being proactive when reading: Academic personal initiative as a predictor of word comprehension development. Manuscript submitted for publication.

Weinstein, C. E., \& Mayer, R. E. (1986). The teaching of learning strategies. In W. M. C. (Ed.), Handbook of research on teaching (pp. 315-327). New York, NY, US: Macmillan.

Wernke, S., Wagener, U., Anschuetz, A., \& Moschner, B. (2011). Assessing cognitive and metacognitive learning strategies in school children: Construct validity and arising questions. International Journal of Research and Review, 6, 19-38.

Wernke, S. (2012). Handlungsnahe Erfassung von Lernstrategien mit Fragebögen - Eine empirische Untersuchung mit Kindern im Grundschulalter [Assessing learning strategies with questionnaires - an empirical investigation with elementary school children]. Oldenburg, Germany: Uni Oldenburg.

Wild, K.-P., \& Schiefele, U. (1994). Lernstrategien im Studium: Ergebnisse zur Faktorenstruktur und Reliabilität eines neuen Fragebogens [Learning strategies of university students: Factor structure and reliability of a new questionnaire]. Zeitschrift für Differentielle und Diagnostische Psychologie, 15, 185-200. 
Wollny, A. (2015). Eigeninitiative in der Kindheit und ihre Bedeutung für die Entwicklung der Lesekompetenz [Personal initiative in childhood and its importance for the development of reading compentence] (unpublished doctoral dissertation). University of Potsdam, Potsdam, Germany.

Wollny, A., Fay, D., \& Urbach, T. (2016). Personal initiative in middle childhood. Learning and Individual Differences, 49, 59-73. doi: 10.1016/j.lindif.2016.05.004

Zimmerman, B. J. (2002). Becoming a self-regulated learner: An overview. Theory into Practice, 41, 64-70. doi: $10.1207 / \mathrm{s} 15430421$ tip4102_2 


\section{Appendix}

Table A.1

Fitness of measurement models to test measurement invariance across time and groups

\begin{tabular}{|c|c|c|c|c|c|c|c|c|c|c|}
\hline Construct & $\chi^{2}(d f)$ & CFI & TLI & RMSEA & SRMR & Comparison & $\Delta \chi^{2}(d f)$ & $\Delta \mathrm{CFI}$ & $\triangle \mathrm{RMSEA}$ & $\triangle \mathrm{SRMR}$ \\
\hline \multicolumn{11}{|l|}{ Personal Initiative } \\
\hline \multicolumn{11}{|l|}{ Across time } \\
\hline Model 1: Configural & $256.222 * * *(85)$ & .971 & .959 & .048 & .035 & -- & -- & -- & -- & - \\
\hline Model 2: Metric & $266.836 * * *(92)$ & .970 & .961 & .046 & .037 & Model 1 vs. Model 2 & $6.66(7)$ & -0.001 & -0.002 & 0.002 \\
\hline Model 3: Scalar & $312.954 * * *(99)$ & .964 & .956 & .050 & .039 & Model 2 vs. Model 3 & $48.30 * * *(7)$ & -0.006 & 0.004 & 0.002 \\
\hline Model 4: Strict & $329.192 * * *(111)$ & .963 & .960 & .047 & .041 & Model 3 vs. Model 4 & $16.30(12)$ & -0.001 & -0.003 & 0.003 \\
\hline \multicolumn{11}{|l|}{ Across groups } \\
\hline Model 1: Configural & -- & -- & -- & -- & -- & -- & -- & -- & -- & -- \\
\hline Model 2: Metric & $473.509 * * *(229)$ & .959 & .957 & .049 & .052 & Model 1 vs. Model 2 & -- & -- & -- & -- \\
\hline Model 3: Scalar & $675.932 * * *(236)$ & .927 & .925 & .065 & .108 & Model 2 vs. Model 3 & $190.43 * * *(7)$ & -0.032 & 0.016 & 0.056 \\
\hline Model 4: Strict & $683.373 * * *(248)$ & .927 & .930 & .063 & .108 & Model 3 vs. Model 4 & $9.68(12)$ & 0.000 & -0.002 & 0.000 \\
\hline \multicolumn{11}{|l|}{ Strategy knowledge ${ }^{a}$} \\
\hline Model 1: Configural & $139.060 * * *(54)$ & .969 & .959 & .056 & -- & -- & -- & -- & -- & -- \\
\hline Model 2: Metric & $129.243 * * *(62)$ & .976 & .972 & .046 & -- & Model 1 vs. Model 2 & $7.09(8)$ & 0.007 & -0.010 & -- \\
\hline Model 3: Scalar & $141.130 * * *(70)$ & .974 & .973 & .045 & -- & Model 2 vs. Model 3 & $6.56(8)$ & -0.002 & -0.001 & -- \\
\hline Model 4: Strict & $146.545 * * *(79)$ & .975 & .978 & .041 & -- & Model 3 vs. Model 4 & $9.97(9)$ & 0.001 & -0.004 & -- \\
\hline
\end{tabular}


Table A.1 (continued)

\begin{tabular}{|c|c|c|c|c|c|c|c|c|c|c|}
\hline Construct & $\chi^{2}(d f)$ & CFI & TLI & RMSEA & SRMR & Comparison & $\Delta \chi^{2}(d f)$ & $\Delta \mathrm{CFI}$ & $\triangle \mathrm{RMSEA}$ & $\Delta \mathrm{SRMR}$ \\
\hline \multicolumn{11}{|l|}{ Reading comprehension } \\
\hline Model 1: Configural & $0.224(2)$ & 1.000 & 1.007 & .000 & .002 & -- & -- & -- & -- & -- \\
\hline Model 2: Metric & $5.616(6)$ & 1.000 & 1.001 & .000 & .025 & Model 1 vs. Model 2 & $5.04(4)$ & 0.000 & 0.000 & 0.023 \\
\hline Model 3: Scalar & $6.496(8)$ & 1.000 & 1.002 & .000 & .029 & Model 2 vs. Model 3 & $1.06(2)$ & 0.000 & 0.000 & 0.004 \\
\hline Model 4: Strict & $15.781(12)$ & .997 & .997 & .024 & .051 & Model 3 vs. Model 4 & $9.71 *(4)$ & -0.003 & 0.024 & 0.022 \\
\hline
\end{tabular}

Note. Written in bold are values of $\triangle$ RMSEA, $\triangle$ CFI and $\triangle$ SRMR that were above the cut-off values recommended by Chen (2007). Higher level of measurement invariance is rejected if $\triangle \mathrm{CFI} \geq-.010$, supplemented by $\triangle \mathrm{RMSEA} \geq .015$ or $\triangle \mathrm{SRMR} \geq-.010$.

${ }^{a}$ When using the WLSMV estimator, Mplus does not provide values for SRMR, and chi-square differences can only be computed with the DIFFTEST option.

${ }^{*} p<.05,{ }^{* *} p<.01 .{ }^{* * *} p<.001$. 
Table A.2

Estimated effects of control variables

\begin{tabular}{|c|c|c|c|c|c|c|c|}
\hline \multirow{3}{*}{$\begin{array}{l}\text { Path (from ...) } \\
\text { Gender }^{\mathrm{a}} \rightarrow \text { T2 Personal initiative }\end{array}$} & \multicolumn{3}{|c|}{ Group 1} & \multicolumn{3}{|c|}{ Group 2} & \multirow{3}{*}{$\begin{array}{c}\begin{array}{c}\text { Group } \\
\text { differences }\end{array} \\
\Delta \chi^{2} \\
3.62\end{array}$} \\
\hline & \multirow{2}{*}{$\begin{array}{c}\beta \\
-.11 * *\end{array}$} & \multicolumn{2}{|c|}{$95 \% \mathrm{CI}$} & \multirow{2}{*}{$\begin{array}{c}\beta \\
-.11^{* *}\end{array}$} & \multicolumn{2}{|c|}{$95 \% \mathrm{CI}$} & \\
\hline & & -0.181 & -0.044 & & -0.174 & -0.042 & \\
\hline $\begin{array}{l}\text { T1 Cognitive ability } \rightarrow \mathrm{T} 2 \text { Personal } \\
\text { initiative }^{\mathrm{b}}\end{array}$ & -.05 & -0.042 & 0.148 & $-.13^{*}$ & -0.234 & -0.015 & $12.77 * * *$ \\
\hline SES $\rightarrow$ T2 Personal initiative ${ }^{\mathrm{b}}$ & .02 & -0.090 & 0.133 & -.00 & -0.098 & 0.091 & $4.20^{*}$ \\
\hline Gender $^{\mathrm{a}} \rightarrow$ T2 Strategy knowledge & -.02 & -0.081 & 0.039 & -.02 & -0.090 & 0.043 & 2.27 \\
\hline $\begin{array}{l}\text { T1 Cognitive ability } \rightarrow \text { T2 Strategy } \\
\text { knowledge }^{\mathrm{b}}\end{array}$ & -.02 & -0.125 & 0.095 & -.07 & -0.187 & 0.043 & $4.17^{*}$ \\
\hline SES $\rightarrow$ T2 Strategy knowledge & -.02 & -0.089 & 0.049 & -.02 & -0.104 & 0.057 & 2.25 \\
\hline Gender $^{\mathrm{a}} \rightarrow$ T2 Reading comprehension ${ }^{\mathrm{b}}$ & .08 & -0.021 & 0.181 & $.15^{* *}$ & 0.045 & 0.253 & $7.18^{* *}$ \\
\hline $\begin{array}{l}\text { T1 Cognitive ability } \rightarrow \mathrm{T} 2 \text { Reading } \\
\text { comprehension }^{\mathrm{b}}\end{array}$ & $-.11 *$ & -0.210 & -0.011 & -.06 & -0.170 & 0.053 & $11.89 * * *$ \\
\hline SES $\rightarrow$ T2 Reading comprehension ${ }^{\mathrm{b}}$ & $.16^{*}$ & 0.032 & 0.290 & $.21 * * *$ & 0.099 & 0.310 & $12.64 * * *$ \\
\hline Gender $^{\mathrm{a}} \rightarrow \mathrm{T} 1$ Personal initiative & $-.10^{* *}$ & -0.172 & -0.034 & $-.10^{* *}$ & -0.171 & -0.030 & 2.57 \\
\hline SES $\rightarrow$ T1 Personal initiative & $.15^{* * *}$ & 0.080 & 0.220 & $.15^{* * *}$ & 0.077 & 0.229 & 1.36 \\
\hline Gender $^{\mathrm{a}} \rightarrow$ T1 Reading comprehension ${ }^{\mathrm{b}}$ & $-.13^{*}$ & -0.228 & -0.022 & -.04 & -0.143 & 0.072 & $4.41^{*}$ \\
\hline SES $\rightarrow$ T1 Reading comprehension ${ }^{b}$ & $.28 * * *$ & 0.186 & 0.381 & $.34 * * *$ & 0.267 & 0.421 & $4.90^{*}$ \\
\hline
\end{tabular}

Note. SES $=$ socioeconomic status.

${ }^{\text {a }}$ female $=1$, male $=2$.

${ }^{\mathrm{b}}$ Path was freely estimated because of a significant $\Delta \chi^{2}$ difference between groups. All other paths were fixed to equality.

${ }^{*} p<.05 .{ }^{* *} p<.01 .{ }^{* * *} p<.001$. 